\title{
Microbially Induced Corrosion in Deep Bedrock
}

\author{
Leena Carpén $^{1, a}$, Pauliina Rajala ${ }^{1, b}$, Malin Bomberg ${ }^{2, c}$ \\ ${ }^{1}$ VTT Technical Research Centre of Finland Ltd, Kemistintie 3, P.O.Box 1000, FI-02044 VTT, \\ Finland
}

\author{
${ }^{2}$ VTT Technical Research Centre of Finland Ltd, Tietotie 2, P.O.Box 1000, FI-02044 VTT, Finland \\ aleena.carpen@vtt.fi, ${ }^{b}$ pauliina.rajala@vtt.fi, 'malin.bomberg@vtt.fi,
}

Keywords: biocorrosion, geomicrobiology, deep biosphere.

\begin{abstract}
This paper covers an overview of recent research of microbially induced corrosion in Fennoscandian terrestrial deep bedrock groundwater environment. The assessment of microbially induced corrosion of metals in the deep bedrock environment has become important in evaluating the long-term safety of disposal of radioactive waste.
\end{abstract}

\section{Introduction}

Deep environments in terrestrial bedrock have been considered potential sites for long-term storage of hazardous waste, such as toxic metals and spent nuclear fuel because they are relatively stable, impermeable, nutrient limited, and show little biological activity. However, highly diverse and numerous populations $\left(10^{3}-10^{6}\right.$ cells $\left.\mathrm{mL}^{-1}\right)$ of microorganisms have been detected hundreds to thousands of meters below the surface in sedimentary, metamorphic and igneous rocks [1]. Several studies have described the composition of these microbial communities, but the ecology and activity of these microbial communities are only now beginning to be revealed [2-4]. For example, the metabolic activity of microorganisms in deep Fennoscandian groundwater has been shown to be low, but the microorganisms are quickly activated when growth substrates become available [2]. In addition, it has recently been shown that microbial communities in the nuclear waste repository environment have the capacity to perform anaerobic methane oxidation coupled to simultaneous production of corrosive acetate and sulphides [3] and that they change in response to changes in the environment [4]. Thus, the potential of the indigenous microbial community to induce corrosion under the prevailing environmental conditions may be significant but is still poorly known. Understanding the metabolic activity of these communities and their response to changing environmental conditions is of profound importance to the long-term safety assessments of hazardous waste disposal in deep subsurface sites. The assessment of microbially induced corrosion of metals in the deep bedrock environment has become important in evaluating the long-term safety of disposal of radioactive waste.

Low and intermediate radioactive waste is produced during the operation and decommissioning of nuclear power plants. The metallic waste mostly consists of carbon steel and stainless steels. In Olkiluoto, operational waste has been disposed of in an underground repository excavated into the bedrock to the depth of 60-100 m below sea level. On the other hand, high-level radioactive waste, such as spent nuclear fuel will be stored in copper canisters in the bedrock, at the depth of about 400-450 meters. The disposal of used nuclear fuel is based on the usage of multiple barriers, copper canister being the most important of these barriers.

In oxygen-free water, the corrosion rate of steels and copper is low, unless the water is very acidic or the microbial activity is high in the environment. The groundwater at the repository depth contains up to $10^{5}$ microbial cells $\mathrm{mL}^{-1}$ with considerable species diversity. Microorganisms may significantly contribute to the corrosion of steels. Microorganisms are also able to accelerate several types of copper corrosion. The activity of microorganisms attached to the surfaces and the properties of formed biofilms are essential factors when considering the possibility of microbially induced corrosion. Under the biofilm the conditions may differ remarkably from the surrounding solution and thus induce circumstances where the corrosion is locally increased. As a consequence 
of corrosion of the metallic waste, radioactive nuclides may be released into groundwater and transferred to neighbouring areas of the repository.

The aim of the research is to characterize microbial biofilms associated with corrosion and study the ability of the indigenous groundwater microbes to produce aggressive corrosive agents. In addition, the ability of microorganisms from deep terrestrial biosphere to benefit from these metallic materials is studied.

\section{Microbially induced corrosion in deep bedrock}

Our studies have covered the long term field testing in actual drill holes inside the bedrock as well as extensive mesocosms studies in the laboratory simulating different scenarios and enabling real-time electrochemical survey of corrosion processes [5-11].

Corrosion of steels. In our laboratory scale simulation experiments biofilm formation on surface of carbon steel was shown to be intensive (Fig. 1). The diversity of the biofilm forming microbial community was vast. In an experiment where the flux of organic nutrients was studied, the biofilm forming community changed in response to nutrients. Concrete slowed the initiation of biofilm formation but did not completely inhibit the process. In the presence of concrete the composition of the microbial community was different from that formed in natural conditions. In our experiments native microbes from groundwater were shown to benefit from the presence of carbon steel [11].

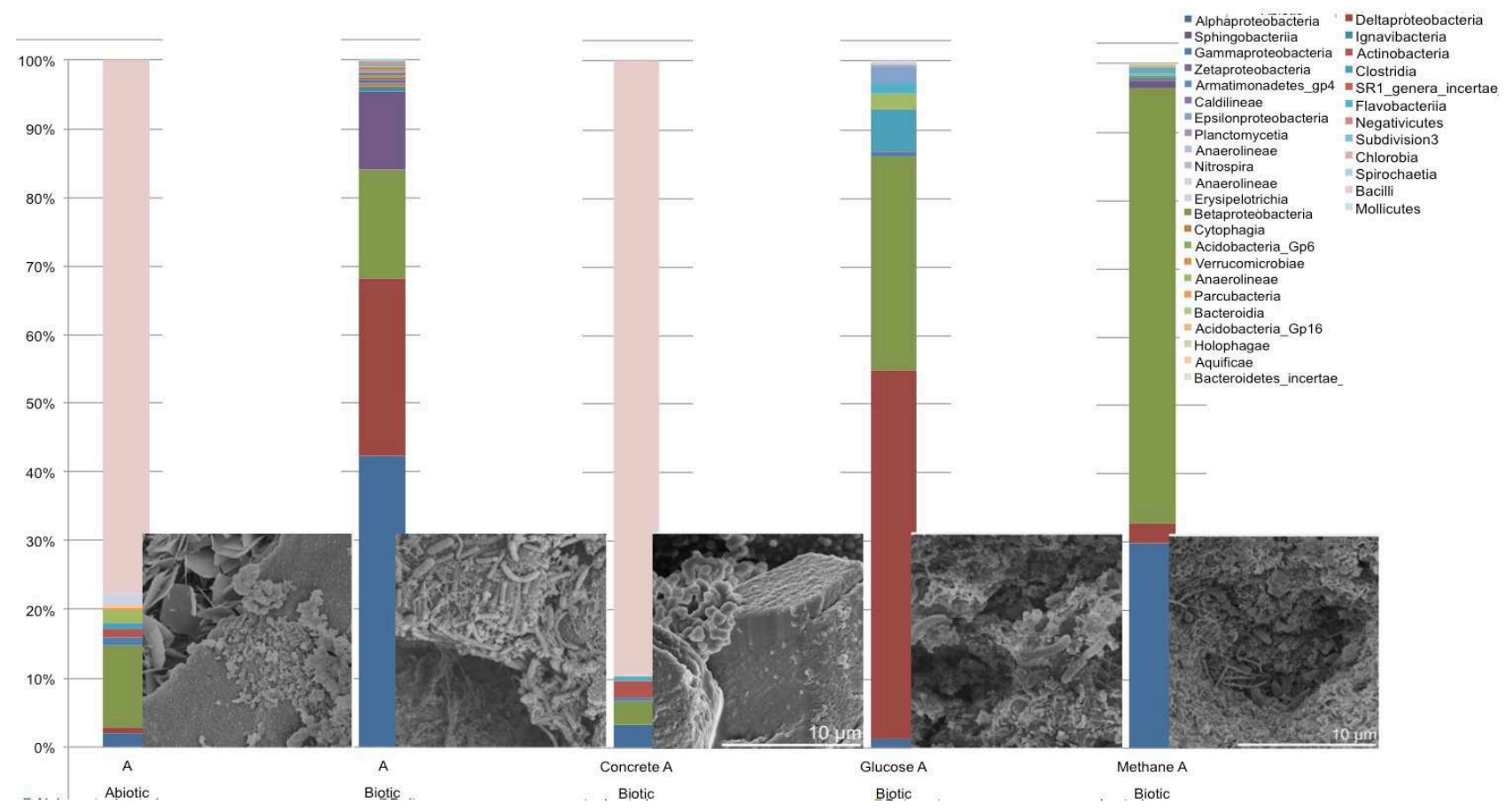

Figure 1. Effect of concrete and nutrition on biofilm forming community.

In general, the detected corrosion rates of steels were higher in the presence of microorganisms compared to the abiotic reference experiments. The increment of nutrients also increased the corrosion rate of carbon steel evaluated by electrochemical methods, whereas the presence of concrete decreased the corrosion rate [5]. In the case of stainless steels a higher corrosion rate was seen in the biotic environment, although the rates were much lower than in the case of carbon steel (Fig. 2).

A long-term field exposure $(\approx 5$ a) showed high corrosion rates, general corrosion rates up to 29 $\mu \mathrm{m} \mathrm{a}^{-1}$ and even higher localized corrosion rates [6,7]. The deposits formed on surfaces were mostly thick and black but some brownish deposits were also present (Fig. 3). The main components were $\mathrm{CaCO}_{3}, \mathrm{FeCO}_{3}, \mathrm{SiO}_{2}$ and metallic iron (Fe). Iron sulphides were probably also present, possibly in the form of $\mathrm{Fe}_{9} \mathrm{~S}_{8}$, and/or $\mathrm{Fe}_{9} \mathrm{~S}_{11}$ [7]. High numbers of microbial cells were discovered adhering on 
the surface of steel coupons using FE-SEM (Fig. 3). The microbial diversity in the biofilm was determined by pyrosequencing. Deltaproteobacteria were the dominant class detected in the biofilm.
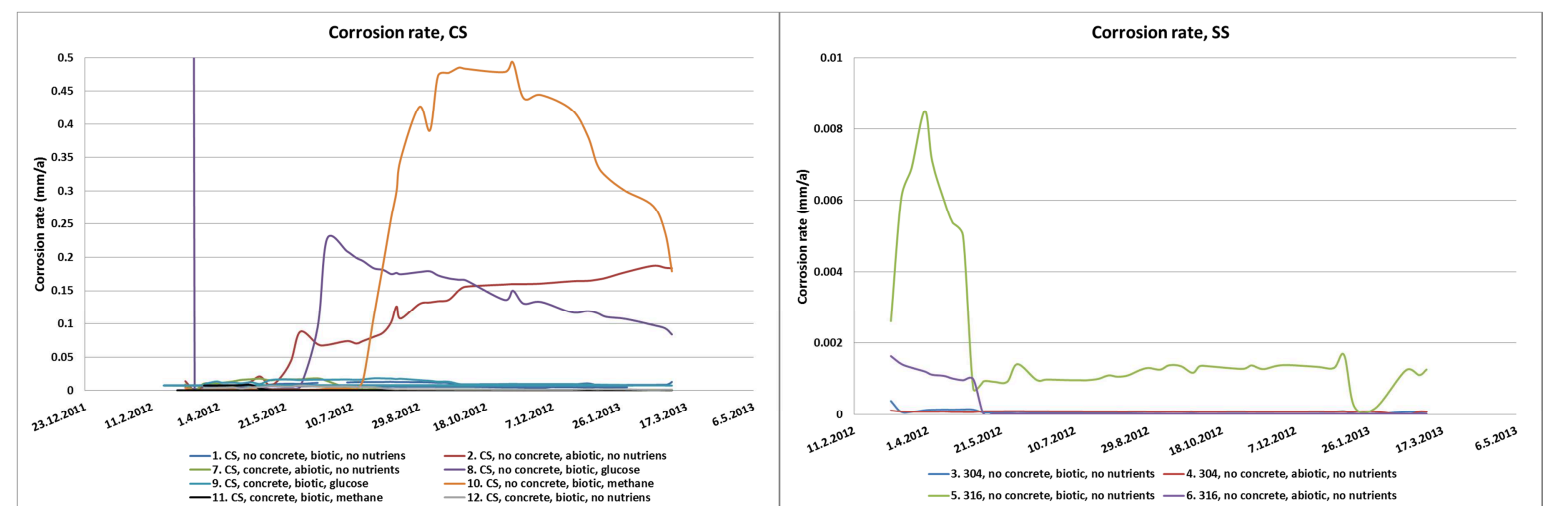

Figure 2.Corrosion rates of carbon steel (left) and stainless steels (right) in ground water with or without nutrient and concrete amendments.
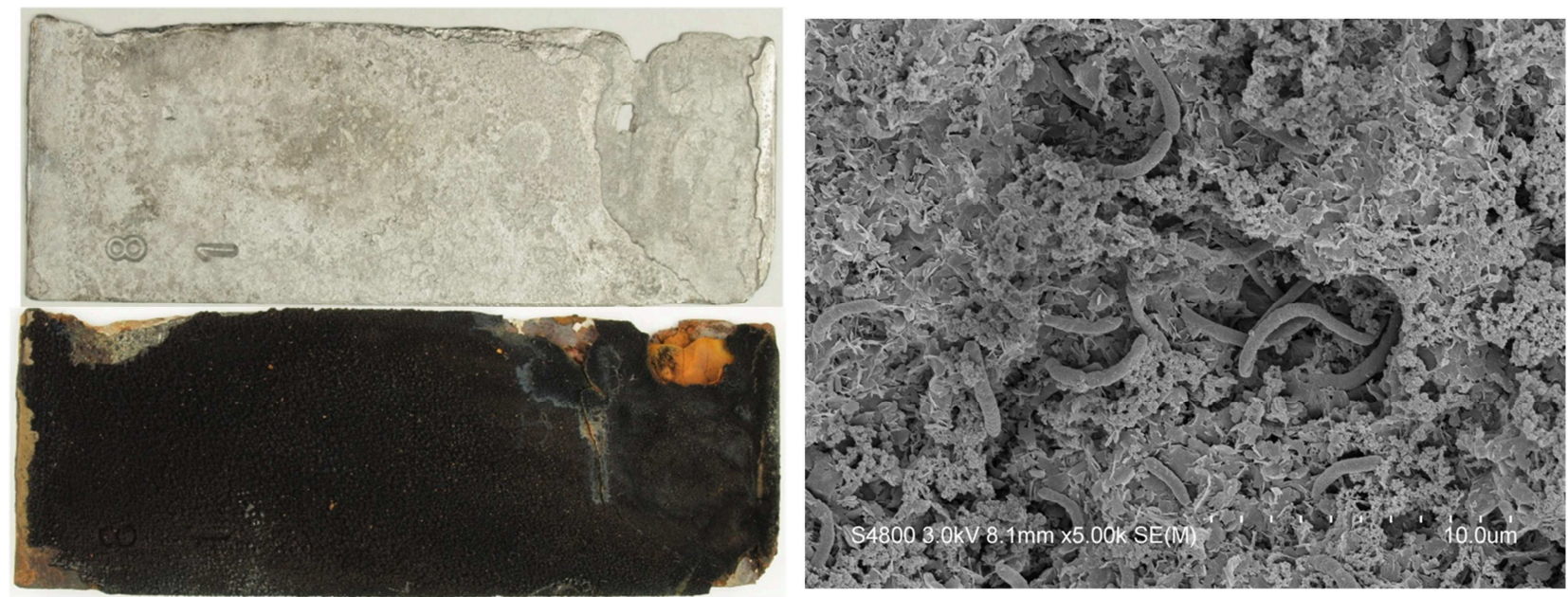

Figure 3. Carbon steel coupons after exposed to ground water at the disposal site (left) and the biofilm between corrosion layers on carbon steel surface after the exposure.

Corrosion of copper. Laboratory simulation studies with microbial enrichment culture (sulfate reducing bacteria) from the repository site aimed to characterize the microbial influence on corrosion of copper under anoxic conditions. Results show the effect of the microbes on the deposits formed on the surface of copper (Figure 4). In addition to metallic copper, chalcocite $\left(\mathrm{Cu}_{2} \mathrm{~S}\right)$ and small amounts of cuprite $\left(\mathrm{Cu}_{2} \mathrm{O}\right)$ and tenorite $(\mathrm{CuO})$ were detected in the biotic specimen. On the surface of the abiotic specimen only cuprite could be detected in addition to metallic copper. Microbes were seen attached on the surface of copper after the enrichment was added (Figure 4). The corrosion rate in biotic environment was up to $7 \mu \mathrm{m} \mathrm{a}^{-1}$ [9]. 

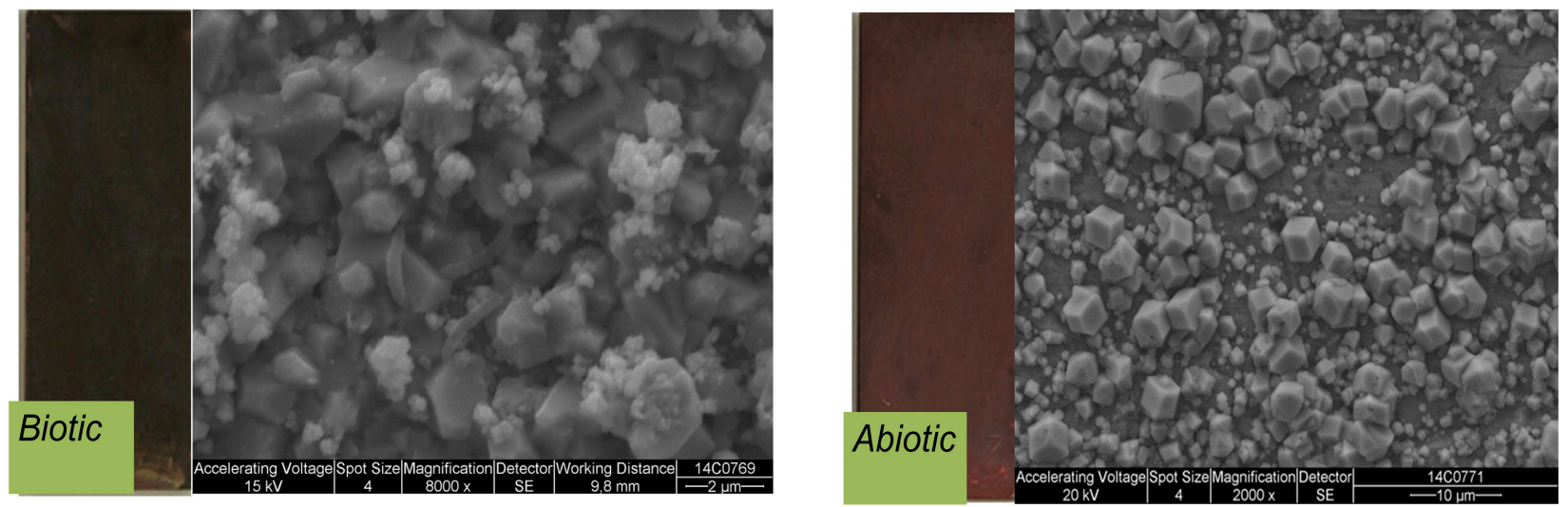

Figure 4. Copper coupons incubated with and without microbial enrichment.

\section{Conclusions}

Indigenous deep groundwater microbes readily attach to metallic surfaces and form biofilms, which facilitate corrosion of both carbon steel and copper. The observed high microbial diversity in the biofilms also provides a multitude of microbial activities, which are not yet fully understood. However, microbial presence and activity clearly increased the corrosion rates and microorganisms were shown to particularly induce localised corrosion.

\section{Acknowledgements}

These works were funded by the KYT2014, Finnish Research Program on Nuclear Waste management, TVO Olkiluoto Nuclear Power Plant and VTT. The authors thank the skilful assistance of Mari Raulio, Mirva Pyrhönen, Taru Lehtikuusi, Marketta Mattila, Tuomo Kinnunen, Arto Kukkonen and Seppo Peltonen in the experimental work.

\section{References}

[1] M. Bomberg, M. Nyyssönen, P. Pitkänen, A. Lehtinen, M. Itävaara. 2015. BioMed Research International, Article ID 979530.

[2] P. Rajala, M. Bomberg, R. Kietäväinen, I. Kukkonen, L. Ahonen, M. Nyyssönen, M. Itävaara. 2015. Microorganisms, 3, 17-33.

[3] K. Pedersen. 2013. The ISME Journal 7, 839-849.

[4] K. Pedersen, A. Bengsson, J. Edlund, L. Eriksson, 2014. Geomicrobiology Journal. 31, $617-$ 631.

[5] L. Carpén, M. Vepsäläinen, P. Rajala, M. Bomberg. 2013. EFC. Eurocorr 2013, September 1 5, 2013 Estoril, Portugal.

[6] L. Carpén, J. Maukonen, S. Salo. 2012. Nace International Corrosion Conference \& Expo 2012, March 11-15, 2012, Salt Lake City, Utah, USA. Nace International, paper nr. C20120001397.

[7] P. Rajala, L. Carpén, M. Raulio. 2014. 19th International Corrosion Congress, 2 - 6 November 2014, Jeju, Korea.

[8] P. Rajala, L. Carpén, M. Vepsäläinen, M. Bomberg and M. Raulio. 2014. Annual Waste Management Conference, VM 2014, 2 - 6 March 2014, Phoenix, Arizona, USA, paper nr. 14391.

[9] L. Carpén, P. Rajala, M. Bomberg. 2014. 19 ${ }^{\text {th }}$ International Corrosion Congress, 2-6 November 2014, Jeju, Korea.

[10] L. Carpén, P. Rajala, M. Vepsäläinen, M. Bomberg and M. Raulio. Nace International Corrosion Conference 9.-13.3. 2014 San Antonio, Texas, USA, paper no. C2014-4035.

[11] P. Rajala, L. Carpén, M. Vepsäläinen, M. Raulio, E. Sohlberg, M. Bomberg. 2015. Frontiers in Microbiology, in press. 